\title{
MNEMONIC CAUSATION, CONSTRUCTION, AND THE PARTICULARITY OF EPISODIC MEMORY ${ }^{1}$
}

\author{
[CAUSAÇÃO MNÊMICA, CONSTRUÇÃO E A PARTICULARIDADE DA MEMÓRIA EPISÓDICA]
}

\begin{abstract}
The idea that episodic memory is memory of particulars is prominent in philosophy. The particularity of remembering, as I will call it, has been taken for granted in most recent theorizing on the subject. This is because the classical causal theory of memory, which has been extremely influential in philosophy, is said to provide a straightforward account of particularity. But the causal theory has been criticized recently, in particular due to its inability to make sense of the constructive character of remembering. In this paper, I argue that recent attempts to account for the constructive character of remembering have failed to account for its particularity. This is either because they depart in important senses from the classical causal theory's account of mnemonic causation or because they give up on mnemonic causation altogether. I then proceed to consider the question of whether we should go back to the classical causal theory of memory to account for particularity. I argue that, despite the widespread idea that the classical causal theory offers a straightforward account of particularity, there are good reasons to reject it. The upshot is that philosophers of memory should consider alternative accounts of particularity that do not revolve around mnemonic causation.
\end{abstract}

KeYwords: Episodic memory; Particularity; Causal theory of memory; Postcausal theories of memory
Resumo: A ideia de que a memória episódica é a memória de particulares é proeminente na filosofia. A particularidade da lembrança, como vou chamá-la, foi tida como certa nas teorias mais recentes sobre o assunto. Isso ocorre porque a teoria causal clássica da memória, que tem sido extremamente influente na filosofia, fornece uma explicação direta da particularidade. Mas a teoria causal foi criticada recentemente, em particular devido à sua incapacidade de dar sentido ao caráter construtivo da lembrança. Neste artigo, argumento que as tentativas recentes de explicar o caráter construtivo da lembrança falharam em explicar sua particularidade. Isso ocorre porque elas se afastam, em sentidos importantes, da explicação da teoria causal clássica da causação mnêmica, ou então porque desistem completamente da causação mnêmica. Em seguida, procuro considerar a questão de saber se devemos voltar à teoria causal clássica da memória para dar conta da particularidade. Argumento que, apesar da ideia difundida de que a teoria causal clássica oferece uma explicação direta da particularidade, há boas razões para rejeitá-la. O resultado é que os filósofos da memória devem considerar explicações alternativas de particularidade que não giram em torno da causalidade mnêmica.

Palavras-chave: Memória episódica; Particularidade; Teoria causal da memória; Teorias pós-causais da memória 


\section{INTRODUCTION}

$\mathrm{T}$ he idea that episodic memory is memory of particulars is prominent in philosophy. The particularity of remembering, as I will call it, has been taken for granted in most recent theorizing on the subject. This is because the classical causal theory of memory, which has been extremely influential in philosophy, is said to provide a straightforward account of particularity due to how it conceives of mnemonic causation. But the causal theory has been criticized recently, in particular due to its inability to make sense of the constructive character of remembering. Recent attempts to account for the constructive character of remembering have resulted in theories of remembering that depart in important senses from the causal theory. This raises the question of whether those theories are capable of providing an account of particularity. In this paper, I will argue that they have failed to provide such an account. In doing so, I will discuss whether that means we should go back to the classical causal theory. I will argue that, in light of the challenges faced by the theory in relation to the constructive character of remembering, philosophers of memory are better off moving away from mnemonic causation in order to account for particularity.

I proceed as follows: Section 2 introduces the particularity of remembering in more detail and considers it in relation to the classical causal theory of memory, in particular to how the latter conceives of mnemonic causation. Section 3 considers the particularity of remembering in relation to recent attempts to account for the constructive character of remembering in philosophy and argues that they have failed to provide an account of particularity. Section 4 raises the question of whether we should go back to the classical causal theory to account for particularity. I offer two reasons to resist that move. In doing so, I suggest that an account of particularity should not be grounded on mnemonic causation.

\section{PARTicularity AND THE Classical CAUSAL THEORY OF MEMORY}

What is the particularity of remembering? Generally speaking, we can say that it refers to the capacity that episodic memory has to represent, or to be about, particular events. However, this definition conflates two distinctive and equally important senses in which we say that memory is of, or is about, particular events: a phenomenological sense and a relational sense (SANT'ANNA, 2020). An example will help motivating this distinction. Consider a memory that I have of my college graduation. When I represent this event in my mind, the memory appears to be about a particular event that I experienced in the past, namely, the event of my college graduation. Because the particularity here has to do with the conscious experience, or the phenomenology of remembering, let us call this the phenomenological particularity of remembering. Having a representation that appears to be about a particular event located in the past does not, however, make that representation a memory of the relevant particular. For instance, I may represent having had a tenth birthday party, and it may appear to me that I am remembering the particular event of my tenth birthday party, even though this event did not happen. In this case, the memory only appears to be of a particular. This brings us to the second sense in which we can say that episodic memory represents a particular, that is, when there is an event in the world that the memory is a representation of, such that it makes the memory in question accurate or true. Because the particularity in this sense has to do with the accuracy or the truth of memory, and as such, with how memory relates to the world, let us call this the relational particularity 
of remembering. ${ }^{2}$ In what follows, I will be concerned with the relational particularity of remembering only. Thus, unless otherwise stated, all occurrences of the term 'particularity' should be taken to mean 'relational particularity'.

Why is the particularity of remembering important? There are three reasons for taking it seriously. The first comes from common sense. In ordinary contexts, we systematically take episodic memories to be about particulars, and more importantly, we refer to those memories as if they were representations of the relevant particular events. For instance, when I want to communicate what happened during my college graduation, I often appeal to my episodic memory of that event to make claims about it. The second motivation is epistemological. The idea is that having an account of how episodic memories can be of particulars allows us to explain how the claims that we make about the past on the basis of episodic memory can constitute knowledge of those events. To use the same example as above, when I claim that "My college graduation took place in a sunny and hot day", that claim can be the basis of a justified true belief about my college graduation because it was formed on the basis of my episodic memory of that particular event (see DEBUS, 2008; SANT'ANNA, 2020). Episodic memory, to put it differently, serves as grounds for our knowledge of the past. Finally, the third motivation is conceptual. Recent attempts to define episodic memory in philosophy and psychology have systematically appealed to the idea that episodic memory represents particular events. This has played a crucial role in distinguishing episodic memory from other related mental states. For instance, some have argued that the distinction between episodic memory and semantic memory should be cashed out in terms of what they represent, with episodic memory being distinctive because of its capacity to represent particular events from the past (e.g., TULVING, 1972; DEBUS, 2008; SANT'ANNA, 2020; FERNÁNDEZ, 2019). Others have attempted to draw this distinction in terms of the distinctive phenomenology of episodic memory. According to them, episodic memory consists in a form of re-experiencing (e.g., TULVING, 1985, 2002; KLEIN, 2015), or knowing what it was like to experience (e.g., MARTIN, 2001; HOERL, 2001; SOTERIOU, 2008, 2018), particular events from the past. Yet others have appealed to the idea that only episodic memory makes us aware of particulars to distinguish episodic memory from episodic imagination (see, e.g., DEBUS, 2014). Thus, providing an account of particularity allows us to vindicate an important idea underlying current theoretical research on memory. ${ }^{3}$

Despite its importance, the particularity of remembering has been overlooked in recent debates in philosophy of memory. I want to suggest that this is due to the influential role played by classical causal theory of memory, originally proposed by Martin and Deutscher (1966), in recent philosophical discussions. The classical causal theory makes two distinctive claims about the nature of remembering, which give us a straightforward account of particularity. The first claim, the causal connection claim, says that remembering a past event requires being causally connected to that event (or to the experience of that event) by means of a memory trace. That is, for me to remember an event $e$, such as my college graduation, I need to have experienced $e$ in the past, a memory trace $M$ must have been formed on the basis of that experience, and $M$ must be responsible for causing my current memory of $e$. The second claim, the locality claim, says that the memory trace responsible for establishing a causal connection between memory and experience is a local entity, in the sense that, for each individual memory representation, there is a unique and discrete memory trace that carries its content (MICHAELIAN and ROBINS, 2018, 21).

Put together, these two claims provide a nice and simple account of the particularity of remembering. They allow us to explain why memories that seem to be 
of particulars are actually memories of particulars. Because there is a unique memory trace that, as a matter of necessity, links a memory back to an event (or the perceptual experience of it), we can specify the relevant kind of relation that allows us to say that a current memory is a representation of a particular past event. Otherwise put, the causal connection claim and the locality claim establish the reference of a memory representation.

Despite offering an account of the particularity of remembering, the classical causal theory has been widely criticized recently for its inability to make sense of the constructive character of remembering (SUTTON, 1998; MICHAELIAN, 2011; ROBINS, 2016). These criticisms have motivated two different strategies. On the one hand, some philosophers have attempted to account for the constructive character of remembering within the broad framework of the classical causal theory. Constructive causal theorists, as we may call them, have attempted to deny the locality claim with the goal of providing an account of the constructive character that is compatible with the causal connection claim (SUTTON, 1998; BERNECKER, 2010; MICHAELIAN, 2011; CHENG and WERNING, 2016). On the other hand, some philosophers have argued that the constructive character of remembering ultimately requires us to give up on the causal connection claim. Postcausal theorists, as we may call them, have therefore attempted to move away from the general framework of the causal theory (MICHAELIAN, 2016; FERNÁNDEZ, 2018, 2019). In the next section, I will argue that both constructive causal theories and postcausal theories have failed to provide an account of the particularity of remembering.

\section{PARTiCularity AND THE CONSTRUCTIVE CHARACTER OF REMEMBERING}

In this section, I will argue that the reason why constructive causal theories and postcausal theories have failed to provide an account of the particularity of remembering is that they depart in important senses from the classical causal theory's account of mnemonic causation. Section 3.1 discusses constructive causal theories and Section 3.2 discusses postcausal theories.

\subsection{Constructive causal theories}

As I pointed out before, constructive causal theories of remembering have criticized the classical causal theory on the grounds that the latter is unable to make sense of the "constructive character" of remembering (see, e.g., MICHAELIAN, 2011). Research on the "constructive character" of memory suggests that, instead of being reproductions of past experiences based on a single source of stored information-i.e., discrete memory traces that store the content of experience-memory representations are reconstructions of past experiences based on different experiential and nonexperiential sources of information that are combined at retrieval (SCHACTER ET AL., 2007, 2012; DE BRIGARD, 2014; MICHAELIAN, 2016; ADDIS, 2018, 2020). As Sutton (1998) points out, "memories are blended, not laid down independently once and for all, and are reconstructed rather than reproduced" (p. 2). Building on this idea, Sutton (1998) then argues that it is wrong to think of memory traces as local and discrete entities that are structural analogues of experience. Influenced by connectionist and distributed accounts of mental representation, he suggests instead that we view memory traces as distributed, in the sense that the contents of memory are distributed across the brain and are connected by associative links differing in their strengths. As 
Michaelian and Robins (2018) point out, according to this view, "a subject's memory is a network in which various items of information are connected as a function of the frequency with which they cooccur in his experience. Each experience activates a certain pattern in the network, but the patterns overlap in a way that precludes distinct contents or vehicles" (p. 21).

To illustrate this idea, consider the following situation. Suppose that during my tenth birthday party, I saw a chocolate cake, some birthday hats sitting on a table, and some balloons attached to a wall. According to distributed accounts, the items of information connected by this experience-i.e., "chocolate cake", "birthday hats on a table", and "balloons attached to the wall" - are responsible for creating a certain pattern of activation in my network, such that, when I remember this event, this pattern is re-activated to bring about the relevant items of information to compose the content of my memory. This pattern and the elements composing it are not, however, exclusively dedicated to storing the content of this particular memory representation, for they may overlap with patterns and items of information formed on the basis of other perceptual experiences. Suppose, for instance, that I went to another birthday party a month later, in which I had a similar perceptual experience to the one I had during my tenth birthday, but in which I saw a strawberry cake sitting on a table and a clown standing right next to the balloons. While the pattern connecting the elements of information in this case differs from the one activated during my experience of my tenth birthday party, the items of information composing each pattern partly overlap. It is for this reason, namely, that items of information composing different memory traces partly overlap, that traces are said to be distributed entities.

Despite proposing a new conception of memory traces, Sutton (1998) does not say much about whether and how that conception fits with the classical causal theory. More recently, Bernecker (2010) and Michaelian (2011) have taken up this challenge. They have attempted to develop a causal theory of memory that makes use of distributed memory traces. Both Bernecker and Michaelian argue that remembering requires the presence of a causal connection to a past experience, but this causal connection is given by a distributed, rather than local, memory trace. They thus endorse the causal connection claim, but they reject the locality claim when they commit to distributed traces. The basic idea is, to use the example above, that a memory of my tenth birthday needs to be caused by a trace formed on the occasion of my experience of that event, but it is not required that this trace be connected only to that experience. Given its distributed nature, it is consistent with the theory that a memory trace is related to more than one experience in the past (see ROBINS, 2016 for a more detailed discussion).

By relying on distributed traces, constructive causal theories have the advantage of accommodating the constructive character of remembering, but that comes at the cost of giving up on the classical causal theorist's account of the particularity of remembering. While constructive causal theorists are able to retain the causal connection claim, which establishes that a memory representation of an event $e$ must be caused by a memory trace $M$ formed by $e$, they cannot retain the locality claim, for there is not a discrete memory trace that carries the content of the memory representation. And the problem with abandoning the locality claim is precisely that one loses the particularity of remembering with it. Without a local conception of memory traces, we cannot draw the causal history of a memory representation. As Robins (2016) points out, "[d]istributed network accounts of memory traces do not provide a way to track the causal history of memories for particular past events" (p. 3009, my emphasis). Thus, we cannot specify the particular experience that gave origin to a memory 
representation. Now, in the absence of a way of specifying this causal history, the question arises as to what allows us to say that a memory representation formed on the basis of a distributed memory trace is a representation of an event $e_{1}$, which strengthened some of the trace connections in the past, as opposed to a representation of an event $e_{2}$, which also strengthened some of the trace connections in the past. It is not clear what the constructive causal theorist should say here. So, despite holding on to the causal connection claim, abandoning the locality claim makes constructive causal theories unable to account for particularity.

It may be objected here that this argument assumes that particularity can only be accounted for in terms of the causal history of a memory. However, the objection goes, it is not clear why constructive causal theorists could not appeal to alternative accounts of particularity. In response, it is worth noting that I am not claiming that constructive causal theorists cannot account for particularity, but only that the resources that are available to the classical causal theory are not available to them. In particular, the classical causal theory's account of mnemonic causation, which is what makes an account of particularity possible, is not available to constructive causal theories. This is an important point that has been neglected by constructive causal theorists, either because they have simply ignored particularity, or because they have taken it for granted that, due to being a causal theory of memory, an account of particularity would follow naturally. Thus, while alternative accounts may be available for them, appealing to those accounts requires first recognizing that the theory is not in a position to account for relational particularity, which is what the argument is trying to establish here.

In summary, constructive causal theories of remembering have failed to provide an account of the particularity of remembering because they depart in important senses from the classical causal theory's account of mnemonic causation.

\subsection{Postcausal theories}

In contrast to constructive causal theories, postcausal theories ${ }^{4}$ of remembering have been developed as attempts to move beyond the causal theory. They do so by denying the causal connection claim. Two postcausal theories have been offered recently: the simulation theory (MICHAELIAN, 2016) and the functionalist theory (FERNÁNDEZ, 2019). To understand the motivations behind the simulationist and the functionalist attempts to abandon the causal connection claim, it will be helpful to discuss them separately. The simulation theory offers two arguments against the causal connection claim. The first is that, given the constructive character of remembering, it is possible, at least in principle, for some mental representations to count as genuine occurrences of remembering even if there is not a causal connection linking back to the original event. The second is that recent developments in psychology, in particular in mental time travel research, suggest that episodic remembering-or mental time travel into the past - is produced by a more general system responsible for mental time travel in subjective time, a system that has been selected primarily for mental time travel into the future - or future-oriented episodic imagining (SUDDENDORF and CORBALLIS, 1997, 2007; SCHACTER et al., 2012). As Michaelian (2016) puts it, episodic memory "is not different in kind from other episodic constructive processes" (p. 103); thus "[w] hat it is for a subject to remember [...] is for him to imagine an episode belonging to his personal past" (p. 111). Thus, given that there could be occurrences of genuine remembering that do not require a causal connection, and given that remembering is a form of imagining and that imagining does not require a causal connection, we should 
reject the causal connection claim.

The functionalist theory offers different reasons to abandon the causal connection claim. According to functionalists, episodic memory is defined by the functional role it plays on a given system. As Fernández puts it,

"[F]or any subject $\mathrm{S}$ and event e, $\mathrm{S}$ remembers e just in case $\mathrm{S}$ has some mental image $\mathrm{i}$ such that $\mathrm{i}$ tends to cause in $\mathrm{S}$ a disposition to believe both that $\mathrm{e}$ happened and that $\mathrm{S}$ experienced e to happen, and i tends to be caused in $\mathrm{S}$ by having experienced e to happen. [...] [R]emembering an event, or having a memory of it, consists in having a mental image that plays the mnemonic role for that event in the subject." (FERNÁNDEZ, 2018, p. 64, my italics)

The idea that a mental state or image "tends to be caused in S by having experienced e to happen" is crucial to understanding why the functionalist rejects the causal connection condition. To see this point more clearly, consider again the birthday party example discussed above. The functionalist says that, for a mental representation (or image) of that event to count as a memory, it is not required that my tenth birthday party (or my experience of it) actually causes my memory of it, but only that it tends to cause it. What exactly it means to say that a particular event (or the experience of it) has the tendency to cause a memory of it is unclear; however, the idea seems to be that a mental state will count as a memory iff it connects the right sort of inputs - which may or may not involve a causal connection by a means of a memory trace - to the right sort of outputs. The obvious analogy here is to more general functionalist accounts of mental states (PUTNAM, 1975). In the same sense that a pain is defined as an internal state that has a tendency to cause certain outputs - e.g., groaning, wincing, etc.-in the presence of certain inputs - e.g., bodily damage - memory too is defined as an internal state that has a tendency to cause certain outputs - i.e., a disposition to believe - in the presence of certain inputs-i.e., the previous experience of an event. Like the simulation theory, the functionalist theory is also motivated by a willingness to account for the constructive character of remembering (FERNÁNDEZ, 2018).

Due to rejecting the causal connection claim, however, postcausalists have failed to offer an account of the particularity of remembering. They accept that there are at least some cases of episodic remembering a particular event that are not appropriately caused by the event in question; that is, I may remember my tenth birthday party even when that memory is not appropriately caused by my experience of tenth birthday party. Since appealing to the causal history of a memory is no longer an option, postcausalists owe us an account of whether and how we can say that the memory in question is a memory of that particular event, as opposed to, say, a memory of a qualitatively identical but numerically distinct event (see DEBUS, 2008).

One may respond here by saying that postcausal theories are compatible with the claim that the vast majority of the occurrences of remembering are caused in an appropriate manner by the relevant past experiences. They only deny that this relationship is necessary for remembering. So, the objection goes, it is not problematic for postcausalists to appeal to causal connections to account for the particularity of remembering. In response, it may be pointed out that, even if we acknowledge this, postcausalists still owe us an account of the particularity of occurrences of remembering that are not appropriately caused by the relevant past experiences. The explanation here will need to appeal to considerations other than causal connections, but it is not clear what such considerations are supposed to be. In addition, if an alternative account of particularity is available for cases in which there is not an appropriate causal connection, then it is not clear what the motivation for accounting 
for the particularity of remembering in terms of causal connections is supposed to be. The postcausalist would be better off simply denying that we need causal connections and by endorsing the alternative account of particularity as applying to all occurrences of remembering, and not just the ones that lack an appropriate causal connection to a past experience.

In summary, postcausal theories of remembering have failed to provide an account of the particularity of remembering in light of their denial of the causal connection claim.

\section{THE CLASSICAL CAUSAL THEORY REVISITED}

The failure of constructive causal theories and postcausal theories to provide an account of the particularity of remembering may prompt some to think that we should go back to the classical causal theory. In this section, I argue that this move should be resisted for two reasons. Section 4.1 considers these reasons in more detail. Section 4.2 suggests that a proper account of particularity need not appeal to mnemonic causation.

\subsection{Two problems for the classical causal theory}

The first problem faced by the classical causal theory has to do with the constructive character of remembering. In other words, the worry is that it is not clear whether particularity can be made compatible with the constructive character of remembering in the context of the classical causal theory. As pointed out in Section 3.1, the constructive character of remembering is the idea that memory representations are not just reproductions of past perceptual representations, but rather reconstructions of those representations that draw on different sources of information, which may involve more than just the original memory trace (MICHAELIAN, 2011, 2016; DE BRIGARD, 2014; ROBINS, 2016). The problem that this idea raises in the context of the particularity of remembering is that, once we admit that a memory representation of a particular event can be caused by two or more memory traces originating in different particular events, we need an account of what makes the memory representation about just one particular. It is not clear, however, whether such an account is available for the classical causal theory.

The classical causal theorist may respond by suggesting that we adopt a 'relevance' condition to account for particularity. According to this approach, only one of the potentially multiple memory traces that may cause a memory representation will be relevant in determining its particularity. As long as this relevance condition is in place, the classical causal theory can accommodate the fact that more than one memory trace can cause a memory representation.

The challenge that this approach faces is that it is difficult to see what such a relevance condition is supposed to look like. One option here would be to account for relevance in terms of content transmission..$^{5}$ According to this alternative, a memory trace $M$ is relevant in establishing particularity iff $M$ contributes with most of the content of a memory representation. To illustrate, consider a memory representation of my tenth birthday party with the following content $C=<$ my parents were there; I played soccer with my friends; it was a sunny day; I had chocolate cake $>$. According to the proposal outlined here, this memory will count as a memory of my tenth birthday party only if (1) there is a memory trace $M$ that links back the perceptual representation of this event, and (2) $M$ is responsible for contributing with most of the content of the 
representation. Thus, if $\mathrm{M}$ contributes the following content $<$ my parents were there; I played soccer with my friends; it was a sunny day $>$, even if there is another memory trace that is responsible for contributing with the content $<\mathrm{I}$ had chocolate cake $>$ to the representation, $M$ will be the memory trace relevant in establishing the particularity of the memory representation.

The problem with this suggestion is that it relies on the assumption that all memories of particulars will satisfy (1) and (2) above. The only way to establish this would be to show that it is impossible, for one reason or another, for one to have a memory of a particular when most of the content of one's memory is not derived from the experience of that particular. While, empirically speaking, it is an open question whether this can be established, a view along these lines seems counterintuitive and theoretically unmotivated. Firstly, the intuition point. Whether or not we endorse a memory representation as a representation of a particular past event does not have to do with where its content comes from. This kind of information is not made available to us when we remember. Admittedly, it seems intuitively plausible that if a memory representation were to contain the content $C$ above, we would not rule it out as a memory of the event in question just because most of its content is not derived from the original experience. Secondly, the theoretical point. Given how constructive processes work in memory, it would not be a surprising result if there were memories like the one just described; in other words, accurate memory representations of particulars in which most of the content does not come from the original experiences, but that are nonetheless taken by the subject to be memories of the relevant particulars. More controversially, as Michaelian (2016) has recently argued, the constructive character of memory seems to imply that no content needs to be transmitted from the original experience for a memory representation to be a memory of a particular. ${ }^{6}$ Thus, simply ruling out those occurrences because they do not meet (2) seems theoretically unmotivated.

Let us now turn to the second problem faced by the classical causal theory. This problem has to do with the locality claim. The locality claim, which is what makes the classical causal theory account of particularity appealing, is at odds with the constructive character of remembering. As Robins (2016) points out, the locality claim is what allows us to say that traces provide us with the causal history, or the reference, of a memory representation. But this, Robins adds, is incompatible with the distributed account of traces given by constructive theories, for this account is designed precisely to explain the constructive character of remembering. While her argument has often been interpreted as an endorsement of the idea that causal theorists should move away from the locality claim, an equally plausible way to interpret it is that a theory cannot be genuinely causal — understood along the lines of Martin and Deutscher (1966) - if it gives up on the locality claim. An alternative way to make the same point in the context of my discussion would be to say that abandoning the locality claim makes the causal theory unable to account for the particularity of remembering. Thus, causal theorists are faced with a dilemma here: either (1) they choose to account for the constructive character of remembering by rejecting the locality claim, in which case they are unable to explain the particularity of remembering, or (2) they choose to account for the particularity of remembering by endorsing the locality claim, in which case they are unable to explain the constructive character of remembering.

An obvious way out of this dilemma would be to offer an account in which the locality claim is compatible with the constructive character of remembering. In a recent work, McCarroll (2018) has argued for a constructive encoding approach to episodic memory, according to which constructive processes take place not only at the time of 
retrieval, but also at the time of encoding. While McCarroll does not deny that there is construction at retrieval, and as such, that more than one memory trace may be the cause of a memory representation, a variation of his view, according to which construction only occurs at encoding, could be developed in an attempt to salvage the locality claim. The idea would be that construction happens at the time of encoding, after which a local memory trace is formed, such that, when it is retrieved to cause a memory representation, it provides the link between the latter and the event of which it is a representation of.

But the problem with a view along these lines is that, while it allows for construction to happen in a framework where memory traces are viewed as locals, it provides a restrictive understanding of what construction in memory is, which is incompatible with empirical findings on the subject. In other words, it is well-known that constructive processes in memory take place not only at encoding, but also at retrieval (ADDIS, 2018, 2020). So, an altered version of the constructive encoding approach is unlikely to be satisfactory in reconciling the locality claim and the constructive character of remembering. Failing that, it is not clear what an account of the constructive character of remembering that is compatible with the locality claim is supposed to look like.

Another way to resist the dilemma is to say that particularity is not incompatible with traces being distributed. On a distributed account, traces are constituted by multiple nodes scattered across a semantic network, with each node corresponding to a particular feature constitutive of the relevant memory they cause. For instance, remembering my tenth birthday party requires activating the nodes HATS, CAKES, BALLOONS, for those were things that I experienced back then. Now, the fact that those nodes are distributed does not mean that, when taken together, they do not constitute a particular memory trace, for all the distributed account implies is that those traces cannot be found in a specific location in the brain. ${ }^{7}$

Despite tempting, this response overlooks a central motivation for speaking of distributed traces to account for the constructive character of remembering. This is that the same set of nodes - e.g., HATS, CAKES, BALLOONS - can and most likely will be used to represent different particular events of the same type. That is, given that hats, cakes, and balloons are typical of birthday parties, the same nodes will be activated when I remember other birthday parties I experienced in my life. Moreover, the connections between these and other nodes will change due to those subsequent experiences. For instance, suppose that, in addition to having hats, cakes, and balloons, various of the birthday parties I have been to after I turned ten had a karaoke. Furthermore, suppose that those experiences created a strong connection between HATS, CAKES, BALLOONS and KARAOKE. This would explain why, when I remember my tenth birthday party, I misremember there being a karaoke there - that is, why my memory constructs a representation that does not, in all of its elements, correspond to my original experience. Thus, even if we grant that the claim that memory traces being distributed across the brain is not in itself incompatible with the idea that they are about particular events, avoiding the dilemma above would require an account of distributed traces that, once they are laid down, (i) they are not altered by any subsequent experiences of similar events, and (ii) those traces can only be used to remember the particular events they were originally meant to be representations of. Since satisfying (i) and (ii) would undermine a central, if not the main, motivation for speaking of distributed traces to account for the constructive character of remembering, this response ultimately fails to avoid the dilemma posed above. 


\subsection{Particularity: Beyond mnemonic causation?}

I have argued that the constructive character of remembering poses an important challenge to accounts of particularity based on mnemonic causation. What should be the next step for those who want to provide an account of particularity? There are three alternatives available here. The first is to stick to mnemonic causation and to try to find a stable balance between an account of particularity in terms of causal connections, on the one hand, and an account of the constructive character of remembering, on the other hand. However, if my argument above is correct, this strategy is unlikely to succeed. In addition, as Michaelian (2016) has recently pointed out, any attempt to develop a constructive causal theory of memory faces the more general challenge of showing how the causal connection claim, namely, that a causal connection is necessary for remembering, can be preserved. While my argument has focused mostly on the locality claim, it appears that, if Michaelian is correct, constructive causal theorists owe us a more general account of how constructive causal theories can be causal theories of memory in the first place. To my knowledge, these questions have not been systematically addressed by constructive causal theorists. ${ }^{8}$

A second option is to reject the claim that episodic memory is about particulars. This strategy has been pursued by Andonovski (2020) in a recent paper. He raises important challenges to an account of the particularity of remembering on the basis of results coming from psychology. If Andonovski is right, then philosophers of memory are better off moving away from particularity. Since, however, it has not been my goal to establish that particularity is a feature of remembering - rather, I have started with the assumption that it is a feature of remembering - I will simply acknowledge that any complete attempt to account for particularity will need to tackle those challenges. That said, it is not unreasonable to assume, at least at this point, that a theory of remembering is expected to explain its particularity. As Andonovski himself acknowledges, that remembering is about particulars is a widespread assumption in the memory literature and, in addition to this idea playing an important role in theoretical research, it allows us to make sense of important epistemological features of remembering (see Section 2).

Thus, a third and final option is to seek alternative accounts of particularity that do not rely on mnemonic causation. Recent discussions on how to characterize the intentional content of episodic memory provide a particularly promising line of investigation. Fernández $(2006 ; 2019)$ has, for instance, argued that episodic memories have self-referential contents, meaning that they represent their causal origins. Although he does not talk about particularity, this view could be developed into an account of particularity. In other words, one could argue that episodic memory is about particulars because it represents itself as being caused by those particulars. I have proposed a similar approach in Sant'Anna (2020). I argue there that the content of episodic memory is partly constituted by the past events themselves. On this view, episodic memories have "gappy contents" that, when properly "filled" by past events, make episodic memories about the relevant particulars. Unlike Fernández, the approach I develop speaks explicitly of particularity and advocates for an account in terms of content. ${ }^{9}$

What intentional approaches along these lines have in common is the fact that they account for particularity in terms of an internal feature to episodic memory understood as a mental state. Instead of appealing to the presence of a causal connection relating memory to experience, which is an external feature to episodic memory understood as a mental state, intentional approaches propose that the relation between episodic memory and the past is an intentional relation, namely, a relation of aboutness 
that is established by its content. An intentionalist account of particularity is thus compatible with the different theories of remembering discussed before. All it requires is the claim that the content of episodic memory is of a certain kind, such that the relevant intentional relation with the past is established. Unless one's preferred account of the content of episodic memory is that it is constituted by a causal relation between memory and experience, whether or not one is committed to the presence of a causal connection for remembering will be irrelevant in providing an account of its content, and, consequently, of its particularity. ${ }^{10}$

It is important to note that I do not mean to suggest this as an account of particularity. Developing a positive proposal is beyond my purposes here. What I want to emphasize is that this last option has a clear advantage over accounts that appeal to mnemonic causation. In other words, because intentionalism accounts for particularity in terms of a feature of episodic memory (i.e., its content) rather than in terms of its relation to past events (i.e., by means of a causal connection), intentionalism is not at odds with an account of the constructive character of episodic memory. An intentionalist is free to choose, depending on his commitments elsewhere in philosophy of memory, whether s/he wants to favor a constructive causal account or a postcausal account of the constructive character of remembering without having to compromise his/her account of particularity. For this reason, I want to conclude by suggesting that, as long as particularity is viewed as a feature of remembering worth explaining, there are options open to philosophers of memory that do not require appealing to mnemonic causation.

\section{CONCLUSION}

In this paper, I argued that recent attempts to move beyond the classical causal theory of memory to account for the constructive character of remembering have not managed to provide an account of the particularity of episodic memory. This is because they depart in important senses from the account of mnemonic causation offered by the classical causal theory, which is what allows the latter to provide a straightforward account of particularity. On the one hand, while constructive causal theories retain the idea that a causal connection is necessary for remembering, their altered understanding of mnemonic causation designed to accommodate the constructive character of remembering leaves out particularity. On the other hand, while postcausal theories explicitly deny the necessity of a causal connection for remembering, they have not offered any alternative accounts of particularity. This limitation raises the question of whether we need to revisit the classical causal theory to account for particularity. I argued that this strategy is unlikely to succeed, for while capable of offering a simple account of the particularity of remembering, the classical causal theory faces serious problems, in particular with respect to the constructive character of remembering. In light of this, I argued that a promising strategy is to look for an account of particularity at the level of the content of episodic memory. Such an account, I suggested, is compatible with both constructive causal and postcausal theories currently on offer in the literature, and as such, provides us with a promising way forward.

\section{REFERENCES}

ADDIS, Donna Rose. Are episodic memories special? On the sameness of remembered and imagined event simulation. Journal of the Royal Society of New Zealand, v. 48 n. 2-3, p. 
64-88, 2018.

ADDIS, Donna Rose. Mental time travel? A neurocognitive model of event simulation. Review of Philosophy and Psychology, v. 11, n. 2, p. 233-259, 2020.

ANDONOVSKI, Nikola. Singularism about episodic memory. Review of Philosophy and Psychology, v. 11, p. 335-365, 2020.

BERNECKER, Sven. Memory: A Philosophical Study. Oxford, Oxford University Press, 2010.

CHENG, Sen; WERNING, Markus. What is episodic memory if it is a natural kind? Synthese,

v. 5, n. 193, p.1345-1385, 2016.

DE BRIGARD, Felipe. Is memory for remembering? Recollection as a form of episodic hypothetical thinking. Synthese, v. 2, n. 191, p. 155-185, 2014.

DEBUS, Dorothea. Experiencing the past: A relational account of recollective memory. Dialectica, v. 4, n. 62, p. 405-432, 2008.

DEBUS, Dorothea. 'Mental time travel': Remembering the past, imagining the future, and the particularity of events. Review of Philosophy and Psychology, v. 5, n. 3, p. 333-350, 2014.

FERNÁNDEZ, Jordi. The intentionality of memory. Australasian Journal of Philosophy, v. 84, n. 1, p. 39-57, 2006.

FERNÁNDEZ, Jordi. The functional character of memory. In: MICHAELIAN, Kourken; DEBUS, Dorothea; PERRIN, Denis. New Directions in the Philosophy of Memory, Routledge, 2018, pp. 52-72.

FERNÁNDEZ, Jordi. Memory: A Self-Referential Account. Oxford University Press, 2019.

HOERL, Christoph. The phenomenology of episodic recall. In McCORMACK, Teresa; HOERL, Christoph. Time and Memory: Issues in Philosophy and Psychology. Oxford University Press, 2001, pp. 315-338.

KLEIN, Stanley B. What memory is. Wiley Interdisciplinary Reviews: Cognitive Science, v. 6, n.1, p. 1-38, 2015.

MARTIN, Charles B.; DEUTSCHER, Max. Remembering. Philosophical Review, v. 75, n. 2, p. 161-196, 1966.

MARTIN, Michael. Out of the past: Episodic recall as retained acquaintance. In McCORMACK, Teresa; HOERL, Christoph. Time and Memory: Issues in Philosophy and Psychology, Oxford University Press, 2001, pp. 257-284.

McCARROLL, Christopher. Remembering from the outside: Personal memory and the perspectival mind. Oxford University Press, 2018.

MICHAELIAN, Kourken. Generative memory. Philosophical Psychology, v. 24, n. 3, p. 323-342, 2011.

MICHAELIAN, Kourken. Mental Time Travel: Episodic Memory and Our Knowledge of the Personal Past. MIT Press, 2016.

MICHAELIAN, Kourken; ROBINS, Sarah K. Beyond the causal theory? Fifty years after Martin

and Deutscher. In: MICHAELIAN, Kourken; DEBUS, Dorothea; PERRIN, Denis. New Directions in the Philosophy of Memory, Routledge, 2018, pp. 13-32.

MICHAELIAN, Kourken; SANT'ANNA, André. Memory without content? radical enactivism and (post) causal theories of memory. Synthese, v. 198, n. 1, p. S307-S335, 2021.

PUTNAM, Hillary. Mind, Language and Reality. Cambridge University Press, New York, 1975.

ROBINS, Sarah K. Representing the past: Memory traces and the causal theory of memory.

Philosophical Studies, v. 173, n. 11, p. 2993-3013, 2016.

SANT'ANNA, André. The hybrid contents of memory. Synthese, v. 197, p.1263-1290, 2020.

SCHACTER, Daniel L.; ADDIS, Donna Rose; BUCKNER, Randy L. Remembering the past to imagine the future: the prospective brain. Nature Reviews Neuroscience, v. 8, n. 9, p. 657-661, 2007.

SCHACTER, Daniel L.; ADDIS, Donna Rose; HASSABIS, Demis; MARTIN, Victoria C.; SPRENG, R. Nathan.; SZPUNAR, Karl K. The future of memory: remembering, imagining, and the brain. Neuron, v. 76, n. 4, p. 677-694, 2012.

SCHELLENBERG, Susanna. The particularity and phenomenology of perceptual experience. Philosophical Studies, v. 149, n. 1, p. 19-48, 2010.

SCHELLENBERG, Susanna. Perceptual particularity. Philosophy and Phenomenological Research, $\mathrm{v}$.

93, n. 1, p. 25-54, 2016.

SOTERIOU, Matthew. The epistemological role of episodic recollection. Philosophy and Phenomenological Research, v. 77, n. 2, p. 472-492, 2008.

SOTERIOU, Matthew. The past made present: Mental time travel in episodic recollection. In

MICHAELIAN, K.; DEBUS, D.; PERRIN, D., editors, New Directions in the Philosophy of Memory, Routledge, 2018, pp. 294-302. 
SUDDENDORF, Thomas; CORBALLIS, Michael C. Mental time travel and the evolution of the human mind. Genetic, Social, and General Psychology Monographs, v. 123, n. 2, p. 133-167, 1997.

SUDDENDORF, Thomas; CORBALLIS, Michael C. (2007). The evolution of foresight: What is mental time travel, and is it unique to humans? Behavioral and Brain Sciences, v. 30, $\mathrm{n}$. 3, p. 299-313, 2007.

SUTTON, John. Philosophy and Memory Traces: Descartes to Connectionism. Cambridge

University Press, 1998.

TULVING, Endel. Episodic and semantic memory. In: TULVING, Endel; DONALDSON, Wayne. Organization of Memory, Academic Press, 1972, pp. 381-402.

TULVING, Endel. Elements of Episodic Memory. Oxford University Press, 1985.

TULVING, Endel. Episodic memory: from mind to brain. Annual Review of Psychology, v. 53, n. 1, p.1-25, 2002.

\section{NOTES}

1 I'm indebted to Kirk Michaelian and an anonymous referee for comments on a previous draft. I'm also grateful to audiences at Massey University and the Centre for Philosophy of Memory at the Université Grenoble Alpes.

2 Both the terms "phenomenological particularity" and "relational particularity" are borrowed from Schellenberg $(2010,2016)$. In Sant'Anna (2020), I provide a more detailed discussion of them in the context of memory.

3 While the above does not establish that episodic memory possesses particularity, it gives us strong theoretical reasons to think that it does. Indeed, one may, in response to these considerations, try to resist committing to particularity (see, e.g., Andonovski (2020) for an attempt along these lines), but since this alternative has been largely unexplored in the literature, and, more importantly, the view that episodic memory does possess particularity is by far the standard one in the literature, I will proceed on the assumption that being able to account for this feature is an advantage of any theory of remembering.

4 This terminology comes from Michaelian and Robins (2018).

5 One important idea for the classical causal theory, as Robins (2016) points out, is that content is transmitted from experience to memory by means of memory traces. For a more detailed discuss of what content transmission amounts to, see Robins (2016); Michaelian and Robins (2018); Michaelian and Sant'Anna (2021).

6 Michaelian does not speak of particularity, but he defends the idea that one can genuinely remember an event even when there is a not a causal connection between memory and experience. Since he takes it for granted that at least some episodic memories are memories of particulars, his argument can be extended to considerations about particularity.

$7 \mathrm{I'm}$ grateful to an anonymous referee for raising this objection.

8 Interestingly enough, Michaelian (2011), who provided one of the first attempts to develop a constructive causal theory of memory, abandons the theory later on by recognizing its inability to preserve the causal connection claim (see Michaelian 2016).

9 A similar approach, from which my own view draws inspiration, is developed by Schellenberg $(2010,2016)$ in relation to perception.

10 This is particularly clear in Fernández's (2019) account of episodic memory. While he advocates for a functionalist approach, which denies the necessity of a causal connection (Fernández 2018; Fernández 2019, ch. 2), his account of the content of memory requires that memory represents itself as being caused by a past experience. 